\title{
Stereoselectivity in the synthesis of 2-azetidinones from ketenes and imines via the Staudinger reaction
}

\author{
Jiaxi Xu \\ Faculty of Science, Beijing University of Chemical Technology, Beijing 100029, \\ People's Republic of China \\ E-mail:jxxu@mail.buct.edu.cn
}

\begin{abstract}
The 2-azetidinone ( $\beta$-lactam) group is a crucial structural feature of one class of significant antibiotics. Its stereochemistry is very important to their biological activities. Stereoselectivity is one of the important issues in the synthesis of 2-azetidines from ketenes and imines via the Staudinger reaction. The origin of the diastereoselectivity in the reaction and influences of reaction conditions on the diastereoselectivity are reviewed. This will provide useful information for understanding and controlling the diastereoselectivity in the preparation of structurally defined 2-azetidinone derivatives.
\end{abstract}

Keywords: Diastereoselectivity, 2-azetidinone, imine, ketene, beta-lactam, Staudinger reaction

\section{Contents}

1. Introduction

2. Origin of the Diastereoselectivity in the Staudinger Reaction

2.1. Identification of the key problem in the diastereoselectivity

2.2. Origin of the diastereoselectivity

3. Influence of Reaction Conditions on the Diastereoselectivity in the Staudinger Reaction

3.1. Influence of ketene generation on the diastereoselectivity

3.2. Influence of solvent on the diastereoselectivity

3.3. Influence of reaction temperature on the diastereoselectivity

3.4. Influence of additives on the diastereoselectivity

3.5. Influence of photo irradiation on the diastereoselectivity

3.6. Influence of microwave irradiation on the diastereoselectivity

4. Conclusions 


\section{Introduction}

The 2-azetidinone ( $\beta$-lactam) unit is a crucial structural feature of one class of significant antibiotics, and its stereochemistry is very important to their biological activities. ${ }^{1}$ For instance, the penicillin and cephalosporin antibiotics possess $c i s$ - $\beta$-lactam units, whereas thienamycins and trinems have trans- $\beta$-lactam moieties. The effective synthesis of optically pure $\beta$-lactams became a desirable goal based on the discovery of penicillin and cephalosporin. ${ }^{2}$ Although most penicillin and cephalosporin-like compounds have been obtained by biosynthesis, by chemical modification of intermediates produced via biosynthesis, or by chemical synthesis, ${ }^{1,2}$ it is still necessary to synthesize some novel $\beta$-lactams, especially compounds with fused $\beta$-lactamheterocyclic rings, for bioassay of antibacterial activity because of the growing resistance of bacteria against penicillin and cephalosporin-like compounds and the need for medicines with more specific antibacterial activity. Some $\beta$-lactam derivatives have also been recognized as inhibitors of human leukocytase elastase, ${ }^{3}$ and agents with new biological activities. ${ }^{4}$

The Staudinger reaction ([2+2] ketene-imine cycloaddition reaction) is regarded as one of the most fundamental and versatile methods for the synthesis of structurally diverse 2-azetidinone derivatives, although many synthetic methods have been developed to date. ${ }^{2,5}$ This reaction has been well investigated experimentally and theoretically during the past decades, ${ }^{6,7}$ and the most widely accepted reaction process is described as follows: ${ }^{5}(1)$ the cycloaddition reaction is a stepwise reaction rather than a concerted one; (2) the reaction is initiated by the nucleophilic attack of an imine to a ketene, giving rise to a zwitterionic intermediate; (3) a conrotatory electrocyclic ring-closure of the zwitterionic intermediate produces the final 2-azetidinone product. The reaction of a monosubstituted ketene with an acyclic imine produces two new stereogenic centers ( $\mathrm{C} 3$ and $\mathrm{C} 4$ in the 2-azetidinone ring), so the product might be cis-, trans-, or a mixture of cis- and trans-2-azetidinone derivatives. Thus, the diastereoselectivity is one of the critical issues in the Staudinger reaction. ${ }^{5}$ Several possible stereochemical processes have been proposed for the formation of cis- and trans- products (Scheme 1). ${ }^{5,6 \mathrm{~d}, 6 \mathrm{f}-\mathrm{g}, 7 \mathrm{~b}-\mathrm{c}, 7 \mathrm{e}}$

In 1989, Brady and Gu claimed that the diastereochemistry was determined by the main resonance structure of the zwitterionic intermediates according to their in-situ infrared spectroscopic investigation. ${ }^{6 \mathrm{~d}}$ In 1991, Hegedus and co-workers ${ }^{6 \mathrm{f}}$ pointed out that the zwitterionic intermediates can isomerize, and the diastereochemistry is determined primarily by the structure of the imines and the character of the free or bound ketenes. In 1993, Cossio and coworkers proposed that the diastereochemistry was decided by the configuration (Z- or $E$-) of the starting imines ${ }^{7 \mathrm{~b}}$ and the torquo-electronic effect of the ketene, ${ }^{7 \mathrm{e}}$ or imine substituents, ${ }^{7 \mathrm{c}}$ on the basis of computational investigations. Georg and his co-workers ${ }^{5,6 \mathrm{~g}}$ suggested that the diastereochemical results can be correlated well with the steric demands of the ketene substituents, and classified the ketenes into three groups (Bose-Evans ketene, ${ }^{5}$ Sheehan ketene, ${ }^{5}$ and Moore ketene ${ }^{5}$ according to their sizes after they summarized the results reported in the literature. ${ }^{5,6 \mathrm{~g}}$ These chemists suggested different models to explain the diastereoselectivity, but their proposals are in conflict to some extent. Except for Georg et al., ${ }^{5,6 \mathrm{~g}}$ each of them only 
focused on the Staudinger reaction involving a particular ketene or imine and failed to provide a universal explanation for the observed complicated stereochemical outcomes. The most pivotal problems regarding the diastereoselectivity remain obscure: (1) How are the $\beta$-lactam products with different configurations generated? (2) Why do different ketenes and imines lead to different stereochemical outcomes, especially, why do the reactions of different ketenes with the same imine generate distinct stereochemical results? (3) Do reaction conditions affect the diastereoselectivity? Therefore, we reinvestigated the diastereoselectivity of the Staudinger reaction recently. Herein, we summarize our experimental results to provide a comprehensive understanding on the origin of the diastereoselectivity and influence of reaction conditions on the diastereoselectivity in the Staudinger reaction.<smiles>[R]N=C([R])N=[N-]</smiles>

A<smiles>CCOc1ccccc1</smiles><smiles>[R]C1=C([O-])[N+]2=C([R])C([R])C1N2[R]</smiles>

C<smiles>[CH]1[CH]C1</smiles><smiles>[R]C1=C([R])[C@@H](O)[N+]([R])=C1[CH]C(C)C</smiles>

D

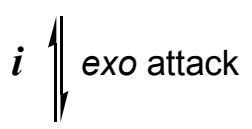<smiles>[R]C1C(=O)N([R18])[C@H]1[CH][SiH2]C</smiles>
cis $-( \pm)-\beta$-lactam

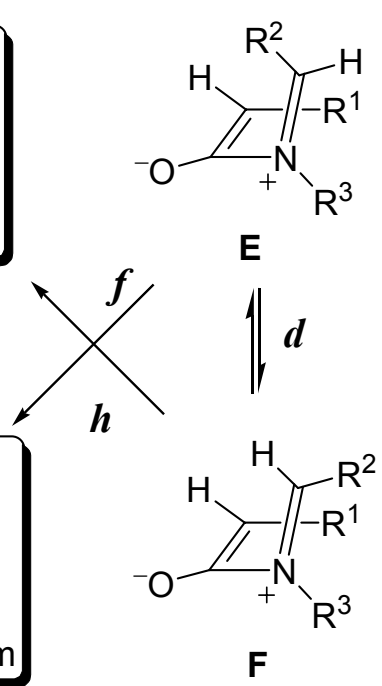

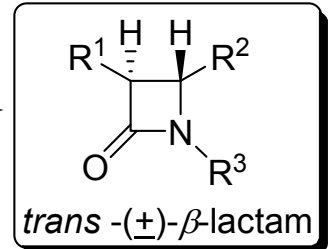

A

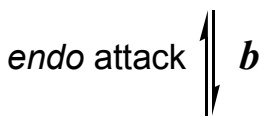

B<smiles>[R]N=C([R])C[N+]=[N-]</smiles>

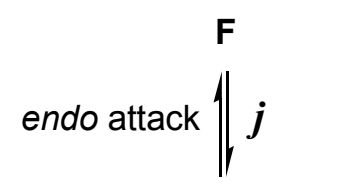

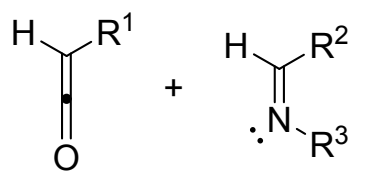

A

G

Scheme 1. Proposed pathways for the formation of cis- and trans-2-azetidinones in the Staudinger reaction. 


\section{Origin of the Diastereoselectivity in the Staudinger Reaction}

\subsection{Identification of the key problem on the diastereoselectivity}

After summarizing the previously proposed stereochemical progresses in the literature (Scheme 1), we can find that the key problem of diastereoselectivity in the Staudinger reaction is which of the following factors determine the diastereoselectivity; (a) the isomerization of the imine moieties in the zwitterionic intermediates generated from imines and ketenes; (b) the configuration of the imines; or (c) the torquo-electronic effect- controlled attacking direction of imines to the ketenes.

First, we performed a series of Staudinger reactions involving cyclic imines and various representative ketenes, including the Bose-Evans ketene $(\mathrm{PhOCH}=\mathrm{C}=\mathrm{O}){ }^{8 \mathrm{a}, \mathrm{b}}$ the Sheehan ketene (PhthNCH=C=O) ${ }^{8 \mathrm{c}}$ and the Moore ketenes $\left(\mathrm{ClCH}=\mathrm{C}=\mathrm{O},{ }^{8 \mathrm{~d}} \mathrm{PhCH}=\mathrm{C}=\mathrm{O},{ }^{8 \mathrm{e}}\right.$ and thiophen-2-yl ketene $^{8 \mathrm{f}, \mathrm{g}}$ ). The results indicate that all the products show the same diastereoselectivities (Scheme $2)$. The stereo-structures of representative products were determined by XRD analyses. $(E)$ Cyclic imines cannot undergo an isomerization, affording specifically cis- products via a conrotatory electrocyclic ring-closure of the zwitterionic intermediates in the Staudinger reaction, whatever the ketenes are - Bose-Evans ketenes, Sheehan ketenes, or Moore ketenes.

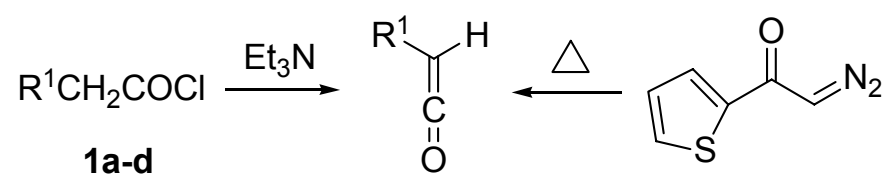

2a

1a: $R^{1}=P h O, 1 b: R^{1}=C l, 1 c: R^{1}=P h t h N, 1 d: R^{1}=P h$

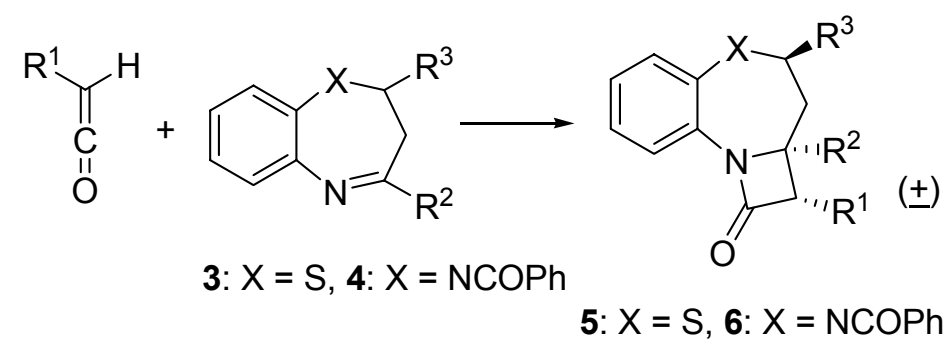

Scheme 2. Staudinger reactions involving various $(E)$-cyclic imines and ketenes.

Secondly, we performed two series of Staudinger reactions, ${ }^{9}$ one involving a ketene and various cyclic imines with different electronic effect substituents and the other involving a cyclic imine and various ketenes with different electronic effect substituents, to determine whether the torquo-electronic effect controlled attacking direction of imines to ketenes determines the diastereoselectivity. All of products show the same diastereoselectivities in the reactions (Scheme 3). (Z)-Cyclic imines cannot undergo an isomerization, affording specifically transproducts via a conrotatory electrocyclic ring-closure of the zwitterionic intermediates in the Staudinger reaction, whatever the electron-rich or electron-deficient ketenes and imines. The 
results indicate that the electronic effect of our investigated ketenes and imines does not affect the attacking direction of imines to ketenes in the Staudinger reactions involving practically used monosubstituted ketenes although the calculation results suggested that the electron-acceptor substituents of ketenes could change the attacking direction of imines to ketenes with the ketenes such as $\mathrm{H}_{2} \mathrm{BCH}=\mathrm{C}=\mathrm{O},{ }^{10}$ which cannot be prepared and used in the practical Staudinger reactions (only used in computational investigations ${ }^{10}$ ).

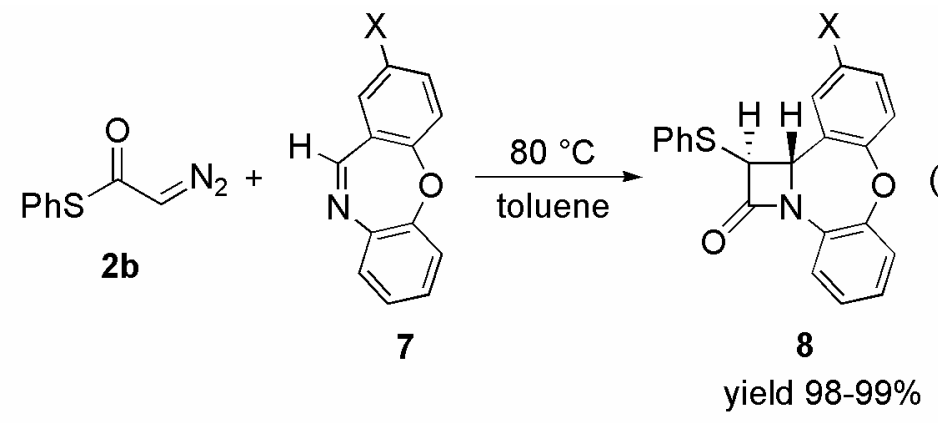

a: $X=\mathrm{Me}, \mathbf{b}: X=\mathrm{H}, \mathbf{c}: X=\mathrm{Cl}, \mathbf{d}: X=\mathrm{NO}_{2}$

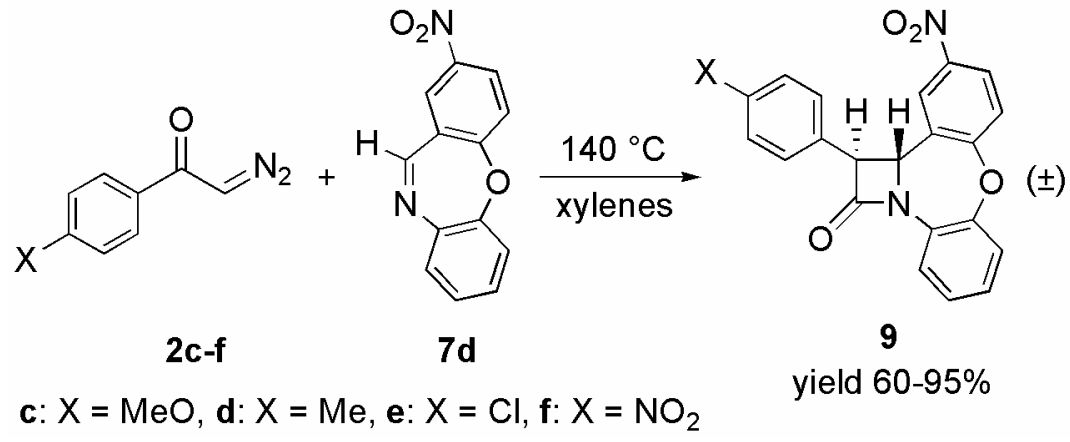

Scheme 3. Staudinger reactions involving various (Z)-cyclic imines and ketenes.

On the basis of our results above, ${ }^{8,9}$ although $(E)$ - and $(Z)$-cyclic imines show different diastereoselectivities, affording cis- and trans-2-azetidinone derivatives, respectively, for linear imines, they exist in the $E$ configuration, ${ }^{11}$ even if they were $N$-acylated. We determined structures with ${ }^{1} \mathrm{H}$ NMR spectra. ${ }^{9}$ Thus, it seems impossible to consider that trans-2-azetidinone derivatives were generated from $(Z)$-linear imines in the Staudinger reaction. On the basis of our recent results, ${ }^{89}$ we consider that the isomerization of the imine moieties in the zwitterionic intermediates generated from imines and ketenes determines the diastereoselectivity in at least most of the Staudinger reaction.

\subsection{Origin of the diastereoselectivity}

Because the zwitterionic intermediates generated from imines and ketenes are important intermediates in the Staudinger reaction, chloride anion $\left(\mathrm{Cl}^{-}\right)$and tertiary amines (such as $\mathrm{Et}_{3} \mathrm{~N}$ ) or pyridine in the Staudinger reactions involving ketenes generated via the elimination of acyl 
chlorides in the presence of a tertiary amine, transition metals in the Staudinger reactions involving ketenes formed from metallocarbenes, and photo irradiation may affect the diastereoselectivity. ${ }^{5}$ It is the best choice to search for a clear reaction system to investigate the origin of the diastereoselectivity under the thermal conditions.

There are three main ways to produce ketenes: ${ }^{5}$ (1) the elimination of acyl chlorides and related derivatives in the presence of a base, (2) the photolysis of metal-carbene complexes, and (3) the Wolff rearrangement of $\alpha$-diazocarbonyl compounds. ${ }^{12}$ Compared with methods (1) and (2), the use of $\alpha$-diazocarbonyl compounds as ketene precursors has a distinct advantage of being without additives (nucleophiles such as chloride anion and tertiary amine) that could affect the diastereoselectivity of the $\beta$-lactam products. However, the Wolff-rearrangement of $\alpha$ diazocarbonyl compounds occurs generally under the catalysis of transition metal (such as silver ion) or under photo- or microwave- irradiation conditions. ${ }^{12}$ Fortunately, after many attempts, we found that $S$-phenyl 2-diazoethanethioate (2b) can rearrange efficiently to give rise to phenylthioketene at $80{ }^{\circ} \mathrm{C}$ and reacts further with various imines to produce $\beta$-lactam derivatives in good yields (Scheme 4). ${ }^{13}$ Thus, the reaction of $\mathbf{2} \mathbf{b}$ with imines was selected as appropriate to investigate the origin of the diastereoselectivity in the Staudinger reaction.

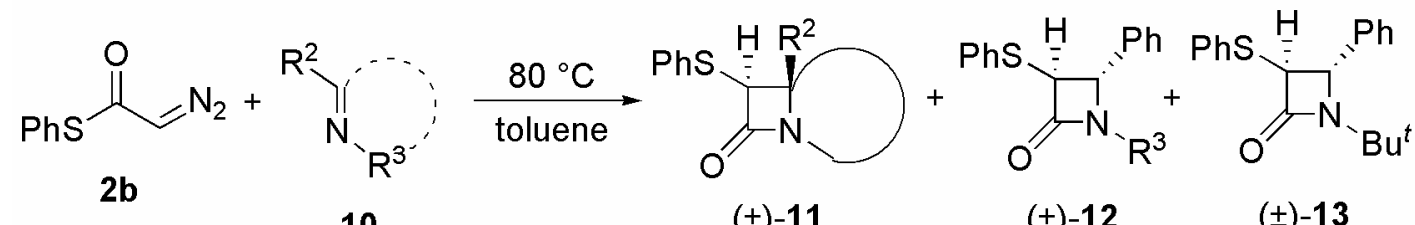

10

$( \pm)-11$

$( \pm)-12$

$( \pm)-13$

Scheme 4. Clean Staudinger reactions with $S$-phenyl 2-diazo-ethanethioate (2b) as ketene precursor under thermal conditions.

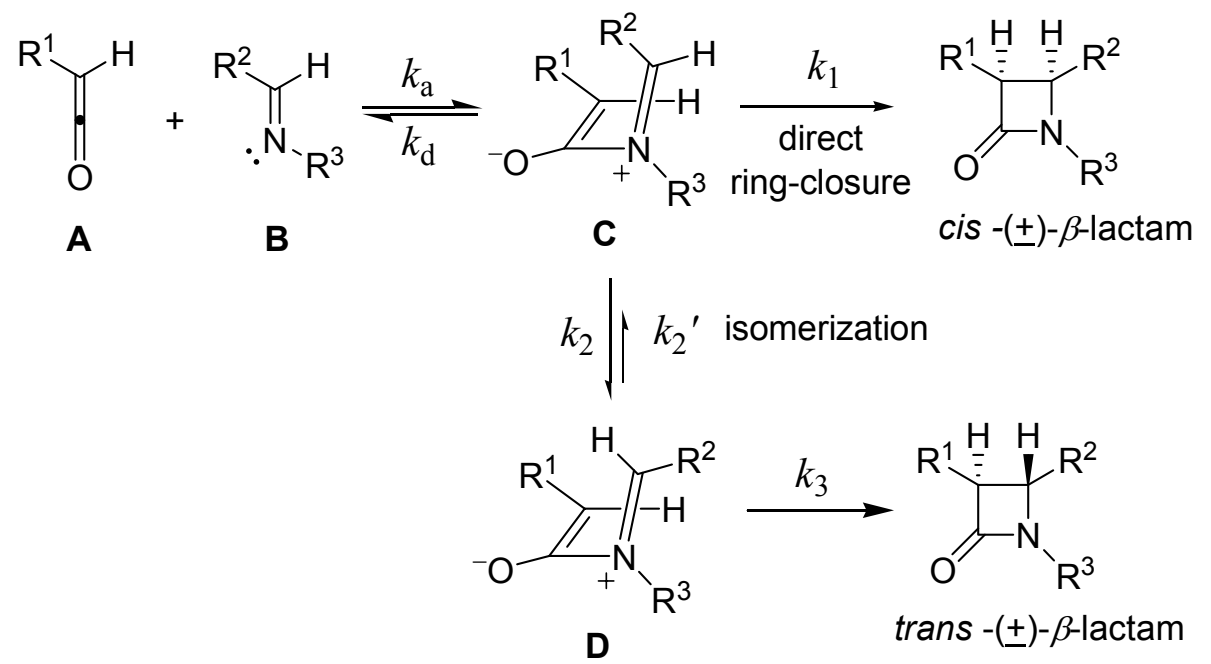

Scheme 5. Suggested mechanism of the Staudinger reaction. 
On the basis of our investigations above, the mechanism of the Staudinger reaction involving mono-substituted ketenes can be proposed as in Scheme 5. The Staudinger reaction is a stepwise reaction involving the nucleophilic attack of an imine to a ketene, giving rise to a zwitterionic intermediate $\mathbf{C}$. The zwitterionic intermediate $\mathbf{C}$ undergoes directly a conrotatory electrocyclic ring closure to produce a cis- $\beta$-lactam product, whereas it undergoes an isomerization of its imine moiety first to form a sterically more favorable intermediate $\mathbf{D}$, which produces the final trans- $\beta$-lactam product via conrotatory electrocyclic ring closure. We assumed that the diastereoselectivity is generated from competition between the direct ring closure $\left(k_{1}\right)$ and the isomerization $\left(k_{2}\right)$ of the imine moiety in the zwitterionic intermediate $\mathbf{C}$. If we can determine relative rates of the direct ring closure $\left(k_{1}\right)$ and the isomerization $\left(k_{2}\right)$ of the zwitterionic intermediate $\mathbf{C}$, we can confirm our assumption.

According to the Curtin-Hammett/Winstein-Holness principle, ${ }^{14}$ the diastereomeric ratio [cis- $] /[$ trans- $]$ can be described as following, because the attack of the imine to the ketene is not related to the diastereoselectivity and $k_{1}, k_{3}$ are close to $k_{2}, k_{2}$.

$[$ cis- $] /[$ trans -$\left.\left.]=k_{2} k_{3}\{[\mathrm{C}]]_{0}+[\mathrm{D}]\right]_{0}+[\text { trans }-]_{0}\right\}+k_{1} k_{3}\left\{[\mathrm{D}] 0_{0}+[\text { trans }-]_{0}\right\}+k_{1} k_{2}{ }^{\prime}\left[\right.$ trans $\left.\left.^{-}\right] 0\right] /\left[k_{1} k_{2}{ }^{\prime}\right.$ $\left\{[c i s-] 0+[\mathrm{C}] 0^{+}[\mathrm{D}] 0\right\}+k_{1} k_{3}\left\{[c i s-] 0^{+}[\mathrm{C}] 0\right\}+k_{2} k_{3}[$ cis- $\left.] 0\right]$

The equation (1) could be simplified as:

$[$ cis- $] /[$ trans- $]=k_{1} / k_{3}{ }^{\prime}\left(k_{3}+k_{2}{ }^{\prime}\right) / k_{2}$

owing to the fact that $[D]_{\mathrm{O}}=[\text { cis- }]_{\mathrm{O}}=[\text { trans- }]_{\mathrm{O}}=0$ in the reaction system. Because the intermediate $\mathbf{D}$ is more stable than the intermediate $\mathbf{C}$, due to its lower steric hindrance, the conversion from $\mathbf{D}$ to $\mathbf{C}$ should be very difficult. That is, $k_{2}$ ' $\rightarrow 0$ in the reaction. Finally, the equation could further be simplified as:

$[$ cis- $] /[$ trans- $]=k_{1} / k_{2}$

for convenient treatment. With the simplified equation (3) in hand, we can determine the relative rates via the measure of the diastereomeric ratio [cis- $] /[$ trans- $]$. We found that benzylidene isopropylamine (15a) is a suitable probe to determine the diastereomeric ratio [cis- $] /[$ trans- $]$ (Scheme 6). ${ }^{9}$

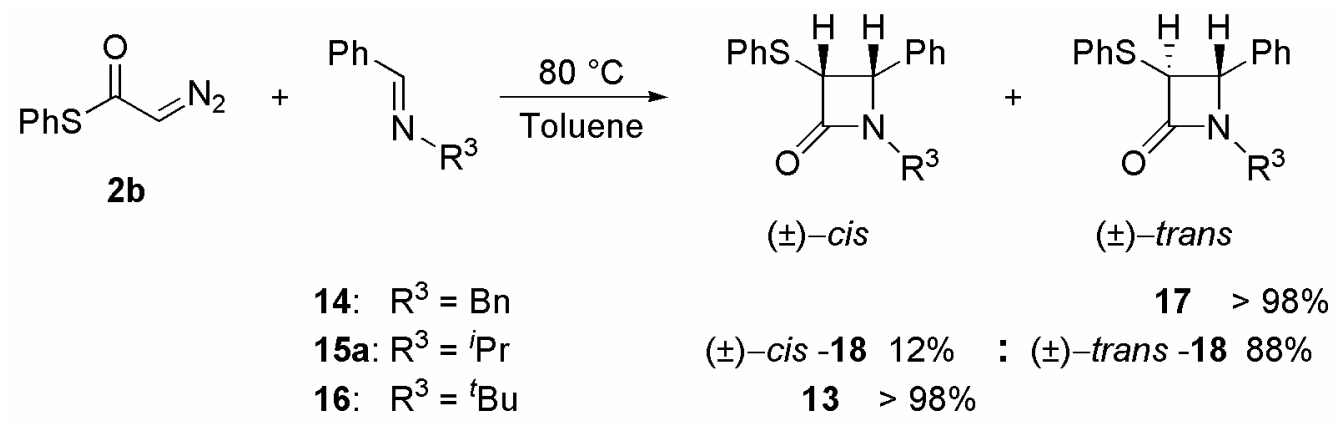

Scheme 6. Steric effect of the $N$-substituent $\mathrm{R}^{3}$ in the Staudinger reaction. 
According to the Hammett equation, each independent rate constant can be correlated to the Hammett constant $\sigma$ (equations 4 and 5).

$\log k_{1, \mathrm{Y}}=\rho_{1} \sigma+\log k_{1, \mathrm{H}}$

$\log k_{2, \mathrm{Y}}=\rho_{2} \sigma+\log k_{2, \mathrm{H}}$

$\log \frac{k_{1, \mathrm{Y}}}{k_{2, \mathrm{Y}}}=\log k_{1, \mathrm{Y}}-\log k_{2, \mathrm{Y}}=\left(\rho_{1}-\rho_{2}\right) \sigma+\log \frac{k_{1, \mathrm{H}}}{k_{2, \mathrm{H}}}=\rho \cdot \sigma+\log \frac{k_{1, \mathrm{H}}}{k_{2, \mathrm{H}}}$

Since the equation (3) shows that cis-/trans- ratio equals to $k_{1} / k_{2}$, the equation (7) can be derived.

$\log \frac{\operatorname{cis}_{\mathrm{Y}}}{\operatorname{trans}_{\mathrm{Y}}}=\log \frac{k_{1, \mathrm{Y}}}{k_{2, \mathrm{Y}}}=\left(\rho_{1}-\rho_{2}\right) \sigma+\log \frac{k_{1, \mathrm{H}}}{k_{2, \mathrm{H}}}=\rho \cdot \sigma+\log \frac{c i s_{\mathrm{H}}}{\operatorname{trans}_{\mathrm{H}}}$

$\rho=\rho_{1}-\rho_{2}$

$\rho_{1}=\rho-\rho_{2}$

Thus, a clear linear relationship between the logarithms of the determined diastereomeric [cis-] / [trans-] ratios and the Hammett constants emerges, in which the slope $(\rho)$ observed in the Hammett analyses represents the difference between the reaction constants of the direct ringclosure $\left(\rho_{1}\right)$ and the isomerization $\left(\rho_{2}\right)$. It is very difficult to determine $\rho_{2}$ (the reaction constants of the isomerization of $\mathrm{N}$-acylated iminiums), but the reaction constants of the isomerization of imines themselves were reported. The reaction constants for $C$-substituents and $N$-substituents of imines are 0.4 and 1.8, respectively, ${ }^{15}$ which could be used approximately as $\rho_{2}$ (the reaction constants of the isomerization of $N$-acylated iminiums). After we have determined the observed $\rho$, we can calculate the reaction constants of the direct ring-closure $\left(\rho_{1}\right)$ with the equation (9). Thus, we can understand the relationship between $k_{1}$ (direct ring-closure), $k_{2}$ (isomerization) and the electronic effect of the ketene and imine substituents.

We conducted three series of Staudinger reactions to determine the reaction constants at $80{ }^{\circ} \mathrm{C}$ in toluene, our optimized reaction conditions. However, the Staudinger reactions of $S$-aryl 2-diazoethane thioates with benzylidene iso-propylamine (15a) show almost no influence of the electronic effect upon the diastereomeric ratios. A series of $\alpha$-diazoarylethanones $\mathbf{2} \mathbf{c}-\mathbf{h}$ with different substituents was synthesized and reacted with imine $15 \mathrm{~b}$ at $140{ }^{\circ} \mathrm{C}$ in xylenes, because compounds $\mathbf{2 c}-\mathbf{h}$ cannot undergo the Wolff rearrangement at $80{ }^{\circ} \mathrm{C}$ (Scheme 7). The results indicate that the cis-/ trans- ratios of the products 19 correlate well with the Hammett constants $(\sigma)$ with a $\rho$-value of -0.63 . Since the reaction temperature affects the reaction constant $\rho$, to get data comparable with the results of the other two series obtained at $80^{\circ} \mathrm{C}$, the reactions were also conducted at $130{ }^{\circ} \mathrm{C}$ in xylenes, and the cis- / trans- ratios of reactions at $80{ }^{\circ} \mathrm{C}$ were calculated according to the Eyring formula, ${ }^{16}$ which have a good correlation with the Hammett constants $(\sigma)$ with a $\rho$-value of -1.1 . Because the different zwitterionic intermediates in this reaction system possess the same imine moiety, the rate constants of isomerization $\left(k_{2}\right)$ are almost the same, i.e., the reaction constant of the isomerization $\rho_{2}$ is about 0 . Accordingly, the reaction constant $\rho_{1}$ should be equal to the experimentally determined $\rho\left(\rho=\rho_{1}-\rho_{2} \approx \rho_{1}=-1.1\right.$ at $\left.80{ }^{\circ} \mathrm{C}\right)$. The negative reaction constant $\rho_{1}$ indicates that the electron-donating groups of the ketenes can 
accelerate the direct ring-closure (increase $k_{1}$ ), while the electron-withdrawing group can decrease the direct ring-closure (decrease $k_{1}$ ).

The other two series of reactions of $S$-phenyl 2-diazoethanethioate (2b) with imines $\mathbf{1 5 a - f}$ and 20a-f were conducted at $80{ }^{\circ} \mathrm{C}$ in toluene. Both series of reactions show good correlations with the Hammett constants $(\sigma)$ with $\rho$-values of 1.62 and 0.31 , respectively, for the $C$ substituents and $\mathrm{N}$-substituents of imines. The corresponding rate constants of the direct ring closure are 2.0 and 2.1, respectively, via the calculations with the equation (9). The positive reaction constants $\rho_{1}$ indicate that the electron-withdrawing groups of the imines can accelerate the direct ring-closure (increase $k_{1}$ ), whereas the electron-donating group can decrease the direct ring-closure (decrease $k_{1}$ ).

Now, we can conclude that the diastereoselectivity is primarily determined by the rate of the direct ring-closure. If the rate constant $k_{1}$ is much larger than $k_{2}$, the $\beta$-lactam product is predominantly cis- ; on the contrary, if $k_{1}$ is much smaller than $k_{2}$, the product is mainly trans. A mixture of cis- and trans-products would be obtained if $k_{1}$ is close to $k_{2}$. The electronic effect of substituent $\mathrm{R}^{1}$ only influences $k_{1}$, and the electronic effects of substituents $\mathrm{R}^{2}$ and $\mathrm{R}^{3}$ mainly influence $k_{1}$. The diastereoselectivity is generated as a result of the competition of the direct ringclosure $\left(k_{1}\right)$ and the isomerization of the imine moiety $\left(k_{2}\right)$ in the zwitterionic intermediates, and $k_{1} / k_{2}$ ratio generally determines the cis- / trans- ratio of the $\beta$-lactam products (Figure 1 ). The results also indicate that the ring-closure step of the Staudinger reaction is most likely to be an intramolecular nucleophilic addition of the enolate to the imine moiety.

After understanding the origin of the diastereoselectivity in the Staudinger reaction, we hope to use our model to rationalize Georg's experiential rule. Two sets of experiments were designed and performed to semi-quantitatively measure the relative rate constants of the direct ringclosure (Scheme 8). When $\mathrm{R}^{1}=\mathrm{PhS}$, the relative rate constant of the direct ring-closure is defined to 1 as a reference, and other relative rate constants were calculated. It has been found that Bose-Evans ketenes have the relative rate constant $k_{1 \text {, rel }}>100$ (e.g. $\mathrm{R}^{1}=\mathrm{PhO}, k_{1 \text {, rel }}=176$ ), Sheehan ketenes have the relative constant $1<k_{1}$, rel $<100$ (e.g. $\mathrm{R}^{1}=\mathrm{PhthN}, k_{1}$, rel $=6$ ), and Moore ketenes have the constants $k_{1 \text {, rel }}<1$ (e.g. $\mathrm{R}^{1}=\mathrm{Ph}, k_{1 \text {, rel }}=0.17$ ). Bose-Evans ketenes with strong electron-donating substituents $\mathrm{R}^{1}$ (such as $O$-alkyl, $O$-aryl, and $N$-alkylaryl), have a distinct preference for cis- $\beta$-lactam formation due to the large rate constant of the direct ringclosure $\left(k_{1, \text { rel }}>100\right)$; Sheehan ketenes produce a mixture of cis- and trans- $\beta$-lactam products due to the moderate rate constants of the direct ring-closure $\left(1<k_{1}\right.$, rel $\left.<100\right)$; and Moore ketenes possessing very weak electron-donating substituents $\mathrm{R}^{1}$ (such as $S$-alkyl, $S$-aryl, alkyl, and aryl) have a strong preference for trans- $\beta$-lactam formation due to the small rate constant of the direct ring-closure $\left(k_{1, \text { rel }}<1\right)$. Our model rationalizes very well the previous experiential classification by Georg et al. 


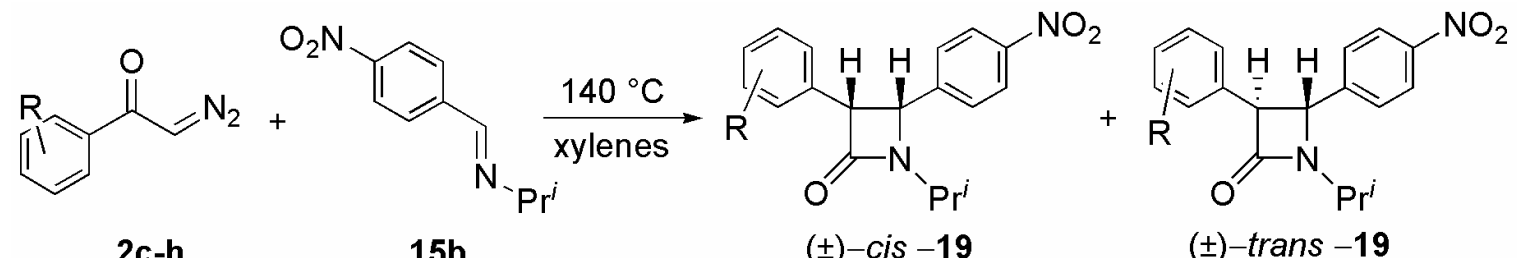

2c-h

$15 b$

$( \pm)-$ cis -19

$( \pm)-$ trans -19

c: $R=4-\mathrm{MeO}, \mathbf{d}: \mathrm{R}=4-\mathrm{Me}, \mathrm{e}: \mathrm{R}=4-\mathrm{Cl}, \mathbf{f}: \mathrm{R}=4-\mathrm{O}_{2} \mathrm{~N}, \mathbf{g}: \mathrm{R}=\mathrm{H}, \mathbf{h}: \mathrm{R}=3-\mathrm{Cl}$

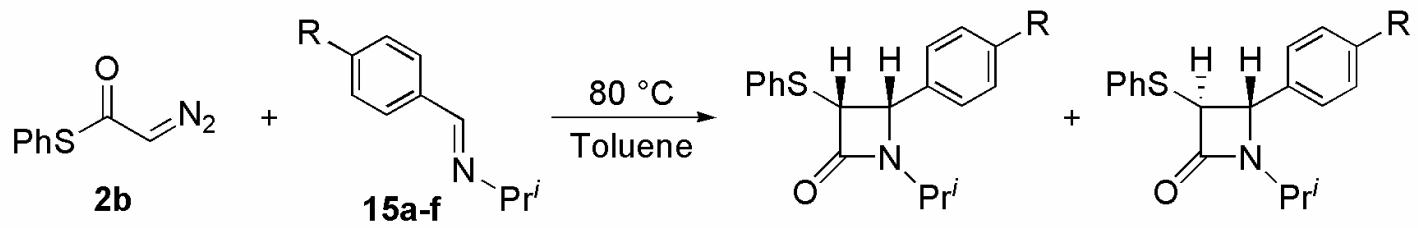
$( \pm)-$ cis $-\mathbf{1 8}$
$( \pm)-$ trans $\mathbf{- 1 8}$

a: $\mathrm{R}=\mathrm{H}, \mathbf{b}:=\mathrm{O}_{2} \mathrm{~N}, \mathbf{c}: \mathrm{R}=\mathrm{MeO}, \mathbf{d}: \mathrm{R}=\mathrm{Me}, \mathbf{e}: \mathrm{R}=\mathrm{Cl}, \mathbf{f}: \mathrm{R}=\mathrm{CF}_{3}$<smiles>[R]c1ccc(N=Cc2ccc([N+](=O)[O-])cc2)cc1</smiles>
$( \pm)-$ cis -21
$( \pm)-$ trans -21

a: $R=M e O, \mathbf{b}: R=M e, c: R=H, d: R=C l, e: R=A c, f: R=O_{2} N$

Scheme 7. Influence of the substituent electronic effect on the diastereoselectivity in the Staudinger reaction.

\section{Competition between the direct ring-closure and the isomerization} controls the relative stereoselectivity.

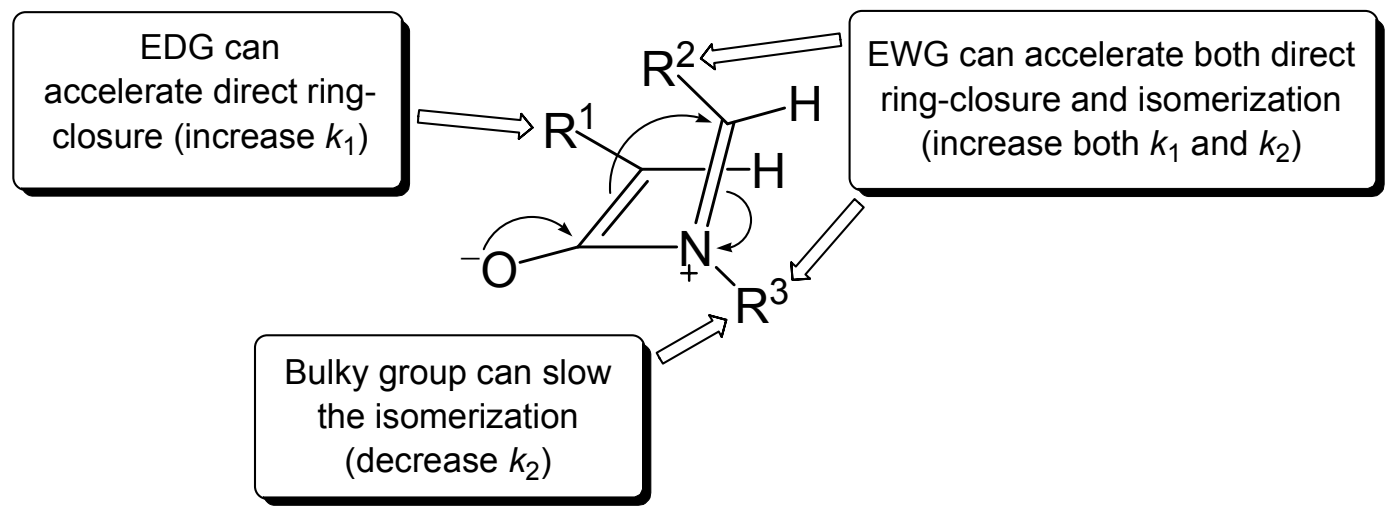

Figure 1. The diastereoselectivity-controlling factors in the Staudinger reaction. 
Table 1. Influence of different ketene substituents on the diastereoselectivity in the Staudinger reaction ${ }^{9}$

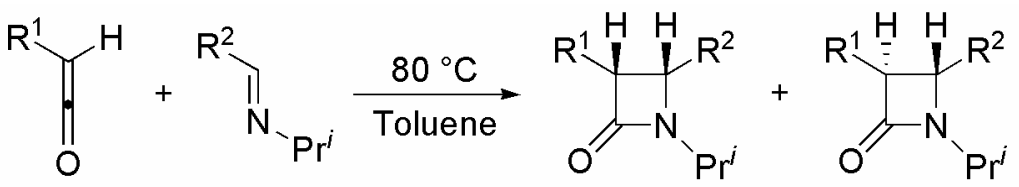

$$
\begin{aligned}
& \text { cis-product trans-product }
\end{aligned}
$$

\begin{tabular}{ccccc}
\hline Entry & $\mathrm{R}^{1}$ & $\mathrm{R}^{2}$ & cis- $:$ trans- & $k_{1, \text { rel }}\left(\mathrm{R}^{1}\right)$ \\
\hline 1 & $\mathrm{PhO}$ & $p$-MeOPh & $88: 12$ & 176 \\
2 & $\mathrm{PhthN}$ & $p$-MeOPh & $19: 81$ & 6 \\
3 & $\mathrm{PhS}$ & $p$-MeOPh & $4: 96$ & 1 \\
4 & $\mathrm{PhS}$ & $p-\mathrm{NO}_{2} \mathrm{Ph}$ & $73: 27$ & 1 \\
5 & $\mathrm{Me}$ & $p-\mathrm{NO}_{2} \mathrm{Ph}$ & $35: 65$ & 0.20 \\
6 & $\mathrm{Ph}$ & $p-\mathrm{NO}_{2} \mathrm{Ph}$ & $32: 68$ & 0.17 \\
\hline
\end{tabular}

It is generally considered that the use of $N$-tert-butyl imines can inhibit the isomerization of the imine moiety, leading to cis- $\beta$-lactam products. ${ }^{6,13}$ This is suitable for explaining the stereochemical outcome of the reaction of $\mathbf{2} \mathbf{b}$ with benzylidene tert-butylamine (Scheme 4). To further support our model, another electron-withdrawing group $\left(-\mathrm{CO}_{2} \mathrm{Et}\right)$ was attached to the ketene $\mathrm{PhSCH}=\mathrm{C}=\mathrm{O}$. The diastereoselectivity dramatically changed from the original cis-/transratio $>98: 2$ to the current 6:94 when it was reacted with benzylidene tert-butylamine. The transproduct, trans-23, generated from the isomerized zwitterionic intermediate, was obtained predominantly because the electron-withdrawing group $-\mathrm{CO}_{2}$ Et caused a significant decrease of the rate of the direct ring-closure (Scheme 8). This also supports our model. The ethoxycarbonyl group- containing ketene was further used for the synthesis of ethyl 2-azetidinone-4-carboxylates, which is the first report on the synthesis of alkyl 2-azetidinone-4-carboxylates via the Staudinger reaction. ${ }^{17}$

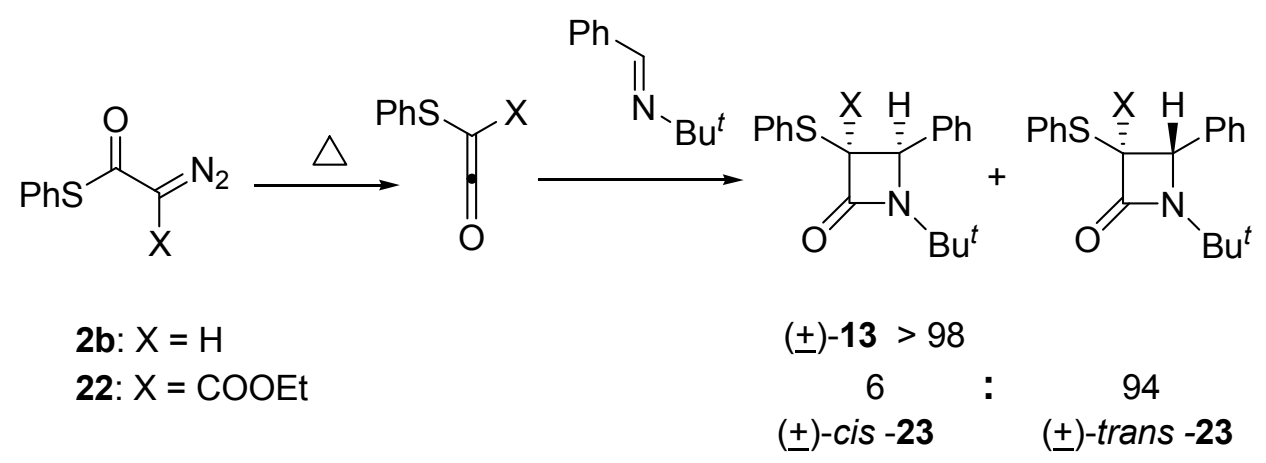

Scheme 8. Effect of the direct ring-closure rate on the diastereoselectivity in the Staudinger reaction. 
Our model can be used to explain and predict the diastereoselectivity in almost all of the reported Staudinger reactions, except for ones involving the imines with $N$-polycyclic aromatic substituents such as 1-naphthyl, 1-anthracenyl, 9-phenanthrenyl, 1-pyrenyl, and 6-chrysenyl with Bose-Evans ketenes due to the existence of peri- hydrogen in the imines. ${ }^{18}$ Cossio and Banik and their co-workers recently explained this abnormal diastereoselectivity via the exo-attack of $(Z)$ imines to the ketenes on the basis of calculation investigation, not experimental results. ${ }^{19}$

\section{Influence of Reaction Conditions on the Diastereoselectivity in the Staudinger Reaction}

\subsection{Influence of the ketene generation on the diastereoselectivity}

Because the elimination of acyl chlorides and the Wolff rearrangement of $\alpha$-diazo- carbonyl compounds are two major methods to generate ketenes, in order to study the influence of the ketene generation on the diastereoselectivity in the Staudinger reaction, we conducted two series of Staudinger reactions, in which the ketenes were generated either via the thermal Wolff rearrangement of $\alpha$-diazo carbonyl compounds ( $S$-phenyl 2-diazoethanethioate and 1diazoacetone) or via the elimination of acyl chlorides (phenylthioacetyl chloride and propionyl chloride), respectively, with imines with different electronic effect substituents (Scheme 9). The results indicate that the formation pathways of ketenes do not obviously affect the diastereoselectivity. ${ }^{20}$
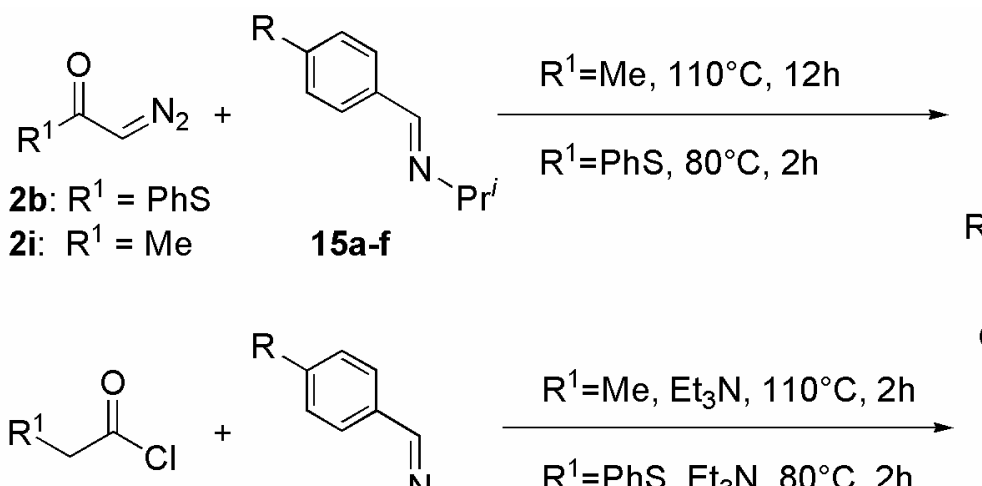

1e: $R^{1}=P h S$

1f: $R^{1}=M e$
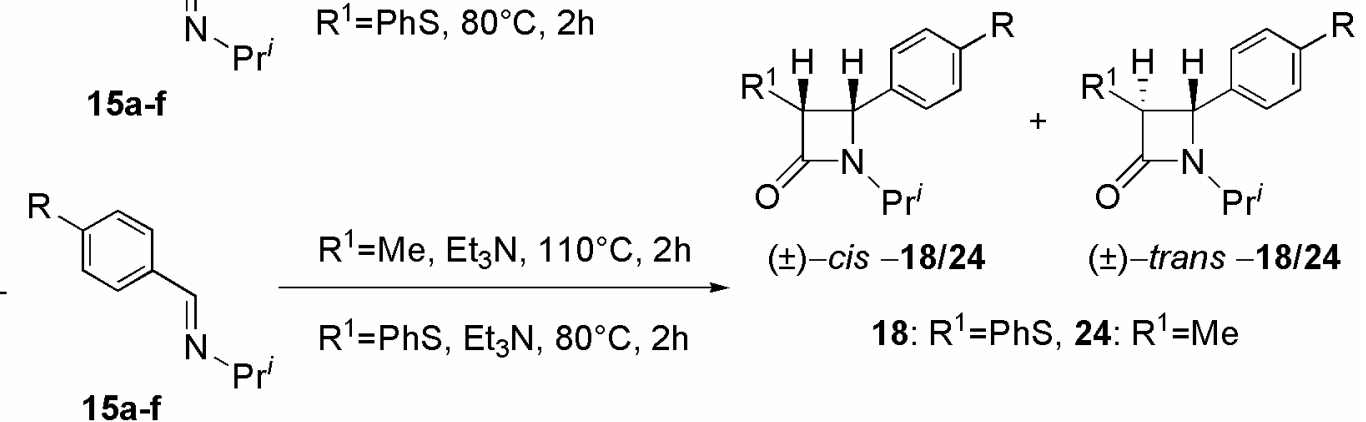

$( \pm)-\operatorname{cis}-18 / 24$

$( \pm)-$ trans $-18 / 24$

18: $R^{1}=P h S, 24: R^{1}=M e$

a: $\mathrm{R}=\mathrm{H}, \mathbf{b}: \mathrm{R}=\mathrm{NO}_{2}, \mathbf{c}: \mathrm{R}=\mathrm{MeO}, \mathbf{d}: \mathrm{R}=\mathrm{Me}, \mathbf{e}: \mathrm{R}=\mathrm{Cl}, \mathbf{f}: \mathrm{R}=\mathrm{CF}_{3}$

Scheme 9. Influence of the ketene generation on the diastereoselectivity in the Staudinger reaction. 


\subsection{Influence of solvent on the diastereoselectivity}

In 1995, Sordo et al. used computational chemistry to investigate the effect of solvent on diastereoselectivity in the Staudinger reaction. ${ }^{21}$ Three years later, Cossio and his co-workers reinvestigated the same effect, again via computational chemistry. ${ }^{7 e}$ However, no detailed experimental investigation has yet been carried out for the effect. The clean reaction of $S$-phenyl 2-diazoethanethioate (2b) with a series of $N$ - iso-propyl imines $15 a-f$ in toluene at $80{ }^{\circ} \mathrm{C}$ was well studied. ${ }^{9}$ This reaction is quite efficient and sensitive to the diastereoselectivity, producing $\beta$-lactam products 18 from predominately trans- to cis- isomers, depending on the electronic effect of the imine substituents. It can be used to investigate the influence of solvents on the diastereoselectivity. We conducted these reactions at $80^{\circ} \mathrm{C}$ in various solvents, including nonpolar (toluene, cyclohexane, and $n$-octane) and polar solvents (acetonitrile, 1,2-dichloroethane, 1,2-dimethoxyethane, and 1,2-dichlorobenzene) (Scheme 10). Very similar diastereoselectivities were obtained for each reaction in different solvents. The results indicate that solvent affects the diastereoselectivity slightly. The amounts of $c i s-\beta$-lactam products increase slightly in the nonpolar cyclohexane and $n$-octane. These results indicate that the non-polar solvents cannot stabilize the zwitterionic intermediates, facilitating the direct ring closure to form cis- products, while polar solvents can stabilize the zwitterionic intermediates and increase their half-life, increasing the isomerization of the imine moiety to generate trans- products. ${ }^{20}$

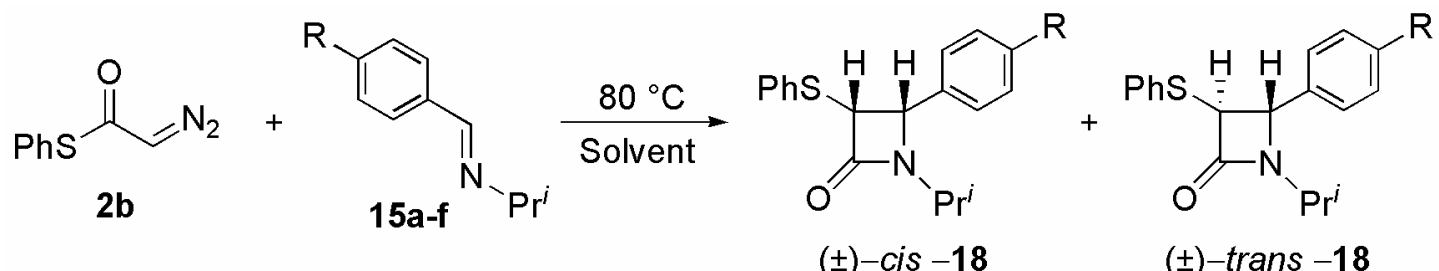

a: $\mathrm{R}=\mathrm{H}, \mathbf{b}:=\mathrm{O}_{2} \mathrm{~N}, \mathbf{c}: \mathrm{R}=\mathrm{MeO}, \mathbf{d}: \mathrm{R}=\mathrm{Me}, \mathbf{e}: \mathrm{R}=\mathrm{Cl}, \mathbf{f}: \mathrm{R}=\mathrm{CF}_{3}$

Scheme 10. Influence of solvent on the diastereoselectivity in the Staudinger reaction.

\subsection{Influence of reaction temperature on the diastereoselectivity}

On the basis of our previous work, ${ }^{9,20}$ to observe obviously different diastereoselectivity of $\beta$ lactam products produced from different ketenes over a broad temperature range, suitable imines should be selected for the different ketenes. For ketenes with methyl-, phenyl-, chloro-, and phenylthio- substituents (the Moore ketenes), which favor trans- $\beta$-lactam products, the imine 15b with $C$ - $p$-nitrophenyl substituent was selected to favor formation of $c i s-\beta$-lactams. For ketenes with phenoxy- and phthalimido substituents (the Bose-Evans- and the Sheehan ketenes), the imine 15c with $C$-p-methoxyphenyl substituent was selected to favor formation of trans- $\beta$ lactams. Staudinger reactions involving different representative ketenes and the corresponding matched imines were conducted over temperatures from 40 to $150{ }^{\circ} \mathrm{C}$ (Scheme 11). 


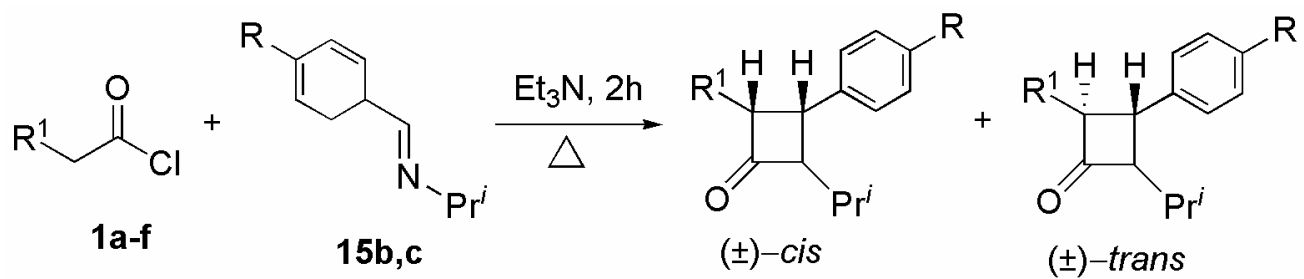

$25,26,27,19 g, 18 b, 24 b$

1a, 25: $\mathrm{R}^{1}=\mathrm{PhO}, \mathbf{1 b}, \mathbf{2 6}: \mathrm{R}^{1}=\mathrm{Cl}, \mathbf{1 c}, \mathbf{2 7}: \mathrm{R}^{1}=\mathrm{PhthN}, 1 \mathrm{~d}, 19 \mathrm{~g}: \mathrm{R}^{1}=\mathrm{Ph}$,

1e, 18b: $R^{1}=P h S, 1 f, 24 b: R^{1}=M e$

15b, 18b, 19b, 24b, 26: $R=\mathrm{NO}_{2}, 15 c, 25,27: \mathrm{R}=\mathrm{MeO}$

Scheme 11. Influence of reaction temperature on the diastereoselectivity in the Staudinger reaction.

The results indicate that most Staudinger reactions show less change in the diastereoselectivity over the higher temperature range than that over the lower temperature range, except for the reaction involving phthalimidoketene. The phthalimidoketene-participating Staudinger reaction shows the most obvious effect of temperature on the diastereoselectivity and a more obvious change over the higher temperature range than that over the lower temperature range. Its diastereoselectivity reverses from cis-/trans- $87: 13$ at $40{ }^{\circ} \mathrm{C}$ to $4: 96$ at $150{ }^{\circ} \mathrm{C}$. For most reactions, the cis- selectivity decreases with increasing temperature. However, the diastereoselectivity of the Staudinger reaction involving methylketene shows no change over the higher temperature range, and that involving phenylthioketene increases with increasing temperature over the lower temperature range. However, the phenylketene-participating Staudinger reaction shows no obvious change in either the lower- or higher temperature regions. A notable and obvious ketene substituent-dependent effect of temperature on the diastereoselectivity in the Staudinger reaction was observed. ${ }^{22}$

On the basis of our current experimental results, it seems that the competition still controls the diastereoselectivity over the whole temperature region, and the rate increases of the direct ring closure and the isomerization are different over the different temperature regions. However, there are two other possibilities for the temperature-dependent diastereoselectivity. One possibility is that sterically unstable cis-products could epimerize to the corresponding sterically more stable trans-products under our reaction conditions at higher temperatures as that reported at $230{ }^{\circ} \mathrm{C} .{ }^{23}$ Moreover, the diastereoselectivities in some Staudinger reactions depend slightly on the temperature, mainly on the structural feature of ketenes, over the high-temperature region.

Thus, the second possibility is that the endo- nucleophilic attack of imines to the ketenes occurred in the high-temperature region because higher temperatures possibly provide enough energy for the nucleophilic endo-attack to get across the higher energy barrier to form the intermediates E. The competition of the imine exo- and endo- attacks to the ketenes may control the diastereoselectivity over the high-temperature region. (Scheme 12). 
To explore the origin of the temperature-dependent diastereoselectivity in the Staudinger reaction over the high-temperature region, first, several representative $c i s-\beta$-lactams $($ cis- $\mathbf{1 8 b}$, 19g, 24b, 25, 26, and 27) were heated, respectively, in mesitylene at $150{ }^{\circ} \mathrm{C}$ for several hours. No epimerization was observed via ${ }^{1} \mathrm{H}$ NMR analysis. This clearly indicates that sterically unstable cis- products cannot be converted into sterically more stable trans- products within our experimental temperature region. Secondly, to distinguish whether the direction of the imine attack to the ketene is the major reason for the temperature-dependent diastereoselectivity in the high-temperature region, we conducted Staudinger reactions between different ketenes (including ketenes with small and bulkier substituents) and an excellent cyclic imine $\mathbf{7 d}$ in mesitylene at $150{ }^{\circ} \mathrm{C}$ (Scheme 13). The cyclic imine favors the direct ring closure because it possesses an electron-withdrawing group $\left(\mathrm{NO}_{2}\right)$, and is favorable to the attack to its endo- side because it possesses the least bulky group $(\mathrm{H})$ on the attacking side of the $\mathrm{C}=\mathrm{N}$ bond. More importantly, it cannot isomerize during the ring closure, owing to its cyclic structure. transProducts 28 were detected specifically by ${ }^{1} \mathrm{H}$ NMR spectra measured directly on the crude reaction mixtures for all of the reactions. The results indicate that the cyclic imine only attacks ketenes from their exo- side to give rise to zwitterionic intermediates, which directly undergo a conrotatory ring closure to produce trans- products specifically.<smiles></smiles>

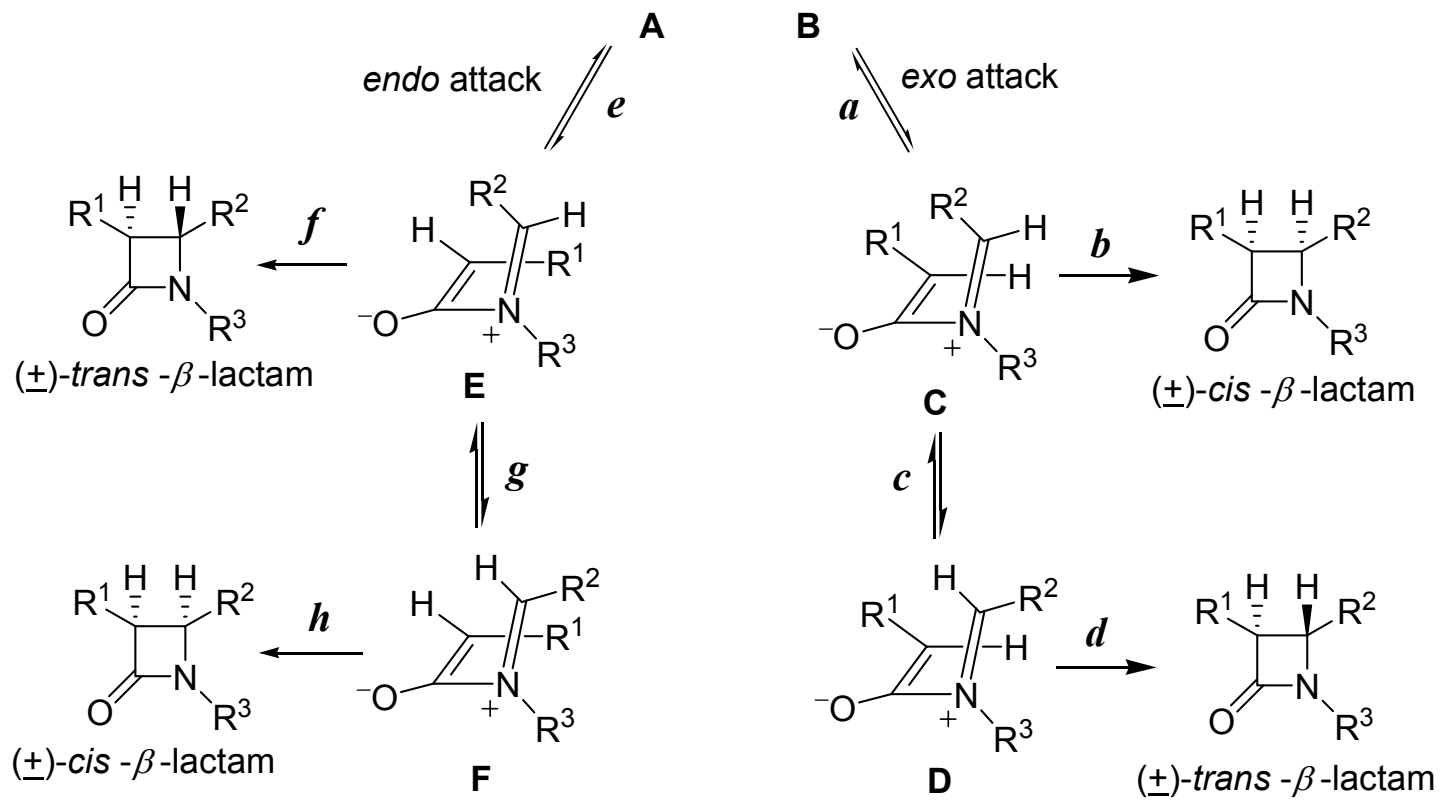

Scheme 12. Possible reaction progress of the Staudinger reaction in the high-temperature region. 


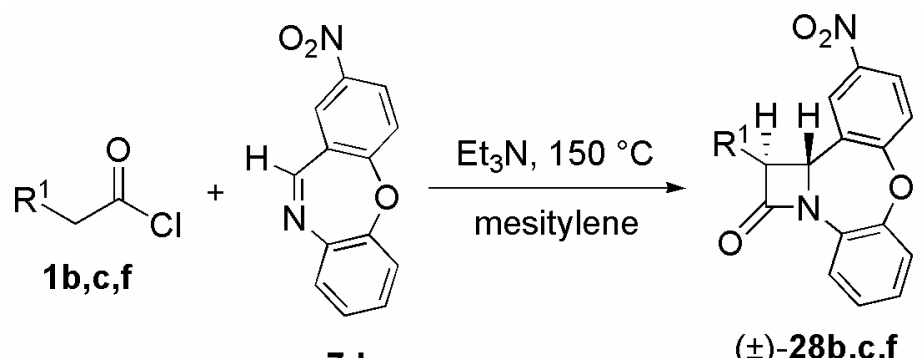

7d

$( \pm)-28 b, c, f$

1b, 28b: $R^{1}=C l, 1 c, 28 c: R^{1}=$ PhthN, 1f, 28f: $R^{1}=M e$

Scheme 13. Staudinger reactions between acyl chlorides and a cyclic imine in the hightemperature region.

Now we can conclude that the origin of the temperature-dependent diastereoselectivity in the Staudinger reaction is the different rate-increases of the direct ring closure and the isomerization of the zwitterionic intermediates over the whole temperature regions investigated. Different zwitterionic intermediates show different characteristics in their rate increases of the direct ring closure and the isomerization at the different temperatures. The isomerization rates of most zwitterionic intermediates increase faster than their direct ring-closure rates with increasing reaction temperature.

The current results indicate that it is the competition between the direct ring closure and the isomerization of the zwitterionic intermediates, rather than the competition of the imine exo- and endo- attacks to the ketenes, that controls the diastereoselectivity in the Staudinger reaction at any temperature.

\subsection{Influence of additives on the diastereoselectivity}

For the Staudinger reaction involving ketenes generated via the elimination of acyl chlorides or related derivatives in the presence of a base, and via the photolysis of metal-carbene complexes, there are some additives (nucleophiles such as chloride anion and tertiary amines, and electrophilic metal carbonyl complexes) that may affect the cis-/trans- ratio of the $\beta$-lactam products in the reaction system.

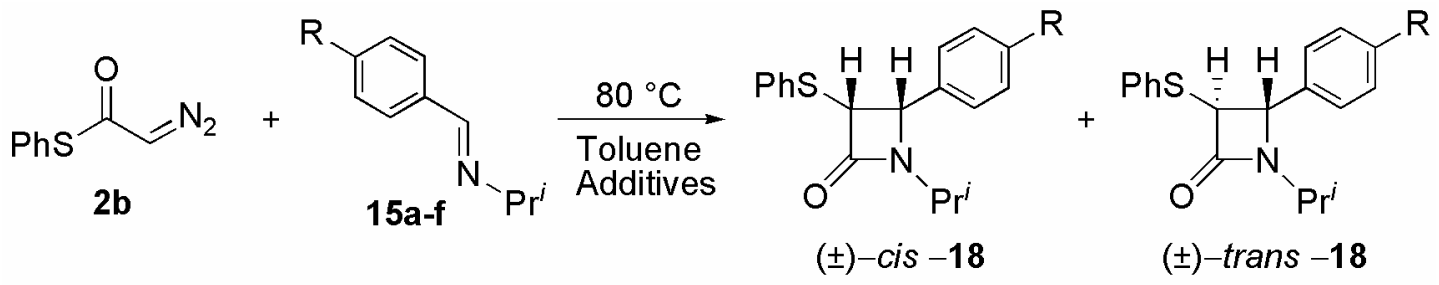

$\mathbf{a}: \mathrm{R}=\mathrm{H}, \mathbf{b}:=\mathrm{O}_{2} \mathrm{~N}, \mathbf{c}: \mathrm{R}=\mathrm{MeO}, \mathbf{d}: \mathrm{R}=\mathrm{Me}, \mathbf{e}: \mathrm{R}=\mathrm{Cl}, \mathbf{f}: \mathrm{R}=\mathrm{CF}_{3}$

Scheme 14. Influence of solvent on the diastereoselectivity in the Staudinger reaction. 
To investigate the influence of additives on the diastereoselectivity, we also chose the clean reactions of $\mathbf{2 b}$ with $\mathbf{1 5 a}-\mathbf{f}$ in toluene at $80{ }^{\circ} \mathrm{C}$ as standard reactions, and then conducted the same reactions in the presence of different additives, including $\mathrm{Et}_{3} \mathrm{~N} \cdot \mathrm{HCl}, \mathrm{TEBA},\left(\mathrm{C}_{4} \mathrm{H}_{9}\right)_{4} \mathrm{~N}^{+} \mathrm{Br}^{-}$, $\mathrm{Et}_{3} \mathrm{~N}$, pyridine, and $\mathrm{Cr}(\mathrm{CO})_{6}$, which usually exist in some Staudinger reactions (Scheme 14). It is found that the diastereoselectivities in the presence of additives are almost the same as those in the standard reactions. This indicates that, when the active species in the Staudinger reaction are ketenes, the usual additives in the reaction system (the by-products generated from the in situ ketene formation) do not obviously affect the stereoselectivity.

\subsection{Influence of photo- irradiation on the diastereoselectivity}

Microwave- and photo-irradiation- induced Staudinger reactions with $\alpha$-diazoketones as ketene precursors have been reported. ${ }^{12}$ They produced trans- $\beta$-lactams exclusively, which was considered uncommon and was explained by the idea that microwave and photo-irradiation could efficiently promote the isomerization of the imines themselves or the imine moiety of the zwitterionic intermediates. However, according to our model, the reported microwave- and photo-irradiation-induced Staudinger reactions belong to the Moore ketene- participating Staudinger reaction because their ketene substituents are protected aminoalkyl groups, favoring formation of trans-products. Thus, we prefer to consider that the low direct ring-closure rate, rather than the microwave or photo-irradiation, is the real reason for the exclusive formation of the trans-products.

Table 2. Comparison of the diastereoselectivity under thermal and photo-irradiation conditions

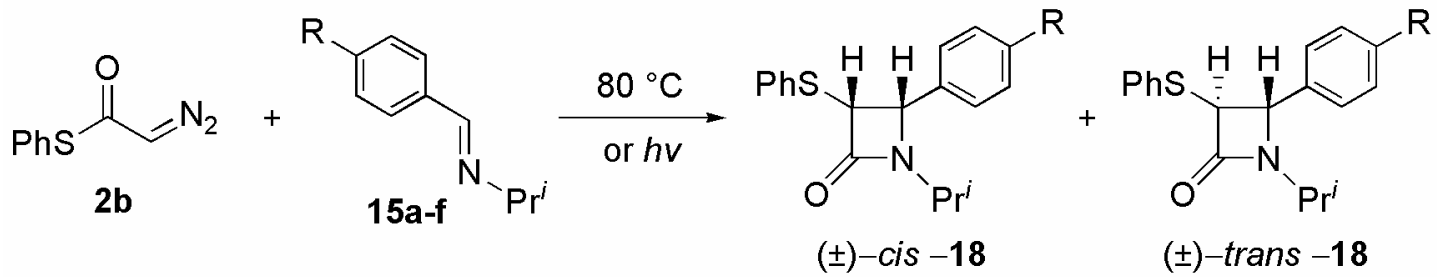

\begin{tabular}{ccccccc}
\hline \multirow{2}{*}{$\begin{array}{c}\text { Reaction } \\
\text { conditions }\end{array}$} & $\mathbf{1 8 c}(\mathrm{MeO})$ & $\mathbf{1 8 d}(\mathrm{Me})$ & $\mathbf{1 8 a}(\mathrm{H})$ & $\mathbf{1 8 e}(\mathrm{Cl})$ & $\mathbf{1 8 f}\left(\mathrm{CF}_{3}\right)$ & $\mathbf{1 8 b}\left(\mathrm{NO}_{2}\right)$ \\
\cline { 2 - 6 } & $4: 96$ & $7: 93$ & $12: 88$ & $17: 83$ & $42: 58$ & $73: 27$ \\
\hline$\Delta$ & $3: 97$ & $8: 92$ & $13: 87$ & $17: 83$ & $28: 72$ & $16: 84$ \\
\hline$v^{a}$ & &
\end{tabular}

To investigate the influence of the photo-irradiation on the diastereoselectivity, the reactions of $\mathbf{2 b}$ with 15a-f were also conducted under the ultraviolet irradiation to compare with the results of the thermal reactions. Interestingly, the results are similar to those in the common thermal reactions (Table 2) for the electron-rich imines. However, the diastereoselectivities show some differences for the electron-deficient imines, especially for the imine $\mathbf{1 5 b}$ with a light sensitive 
nitro group, affording to trans-product as a majority. No specific trans-product was obtained exclusively. The results show that the influence of the photo-irradiation on the diastereoselectivity is limited, and that the diastereoselectivity is predominately controlled by structural features of the ketenes and imines, and not the reaction conditions. ${ }^{9}$

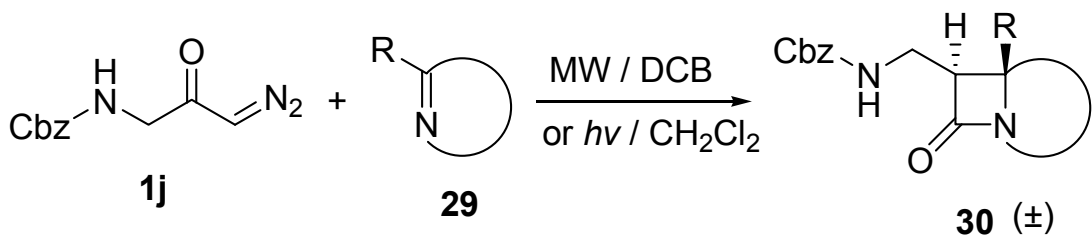

Scheme 15. Influence of photo- and microwave irradiation on the diastereoselectivity in the Staudinger reaction.

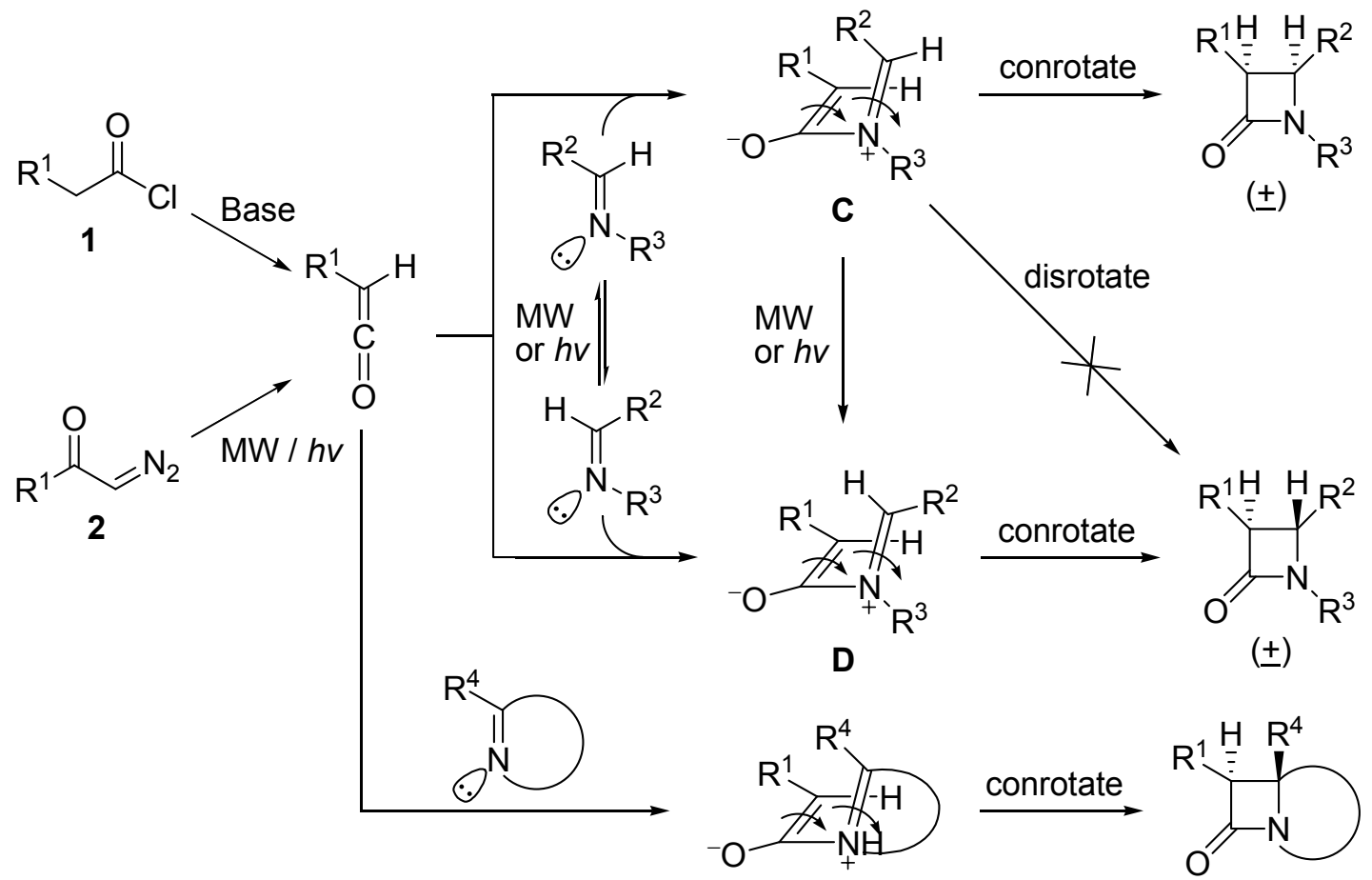

$( \pm)$

Scheme 16. Stereochemical progress of the Staudinger reaction under photo- and microwaveirradiation conditions.

To further confirm the influence of the photo-irradiation on the diastereoselectivity, we also conducted the photo-irradiated Staudinger reaction involving cyclic imines with $\alpha$-diazo ketones, as reported previously (Scheme 15). ${ }^{12}$ The results indicate that the photo-irradiation does not affect the diastereoselectivity. They also show that the zwitterionic azabutadiene-type intermediates generated from imines and ketenes undergo only a conrotatory ring closure to 
produce $\beta$-lactams. This reveals the inapplicability of the Woodward-Hoffmann rule to the photo-irradiation induced Staudinger reaction (Scheme 16). ${ }^{24}$

\subsection{Influence of microwave irradiation on the diastereoselectivity}

Manhas and co-workers reported that microwave irradiation controlled the diastereoselectivity in the Staudinger reaction. ${ }^{25}$ This is contradictory to our previous result that no effect of microwave irradiation on the diastereoselectivity was observed in several special examples with $N$ benzylidene tert-butylamine as an imine. ${ }^{9}$ We considered the microwave-controlled diastereoselectivity possibly resulted from different temperatures generated under different microwave power outputs. ${ }^{25}$ On the other hand, it is still not clear whether the special microwave effect (also called the non-thermal microwave effect) exists in microwave-assisted organic reactions $^{26}$ and whether microwave irradiation affects the stereoselectivity, ${ }^{27}$ although some careful experiments indicate that no non-thermal microwave effect exists in the microwaveassisted reactions. $^{28}$

To compare with our previously reported results, ${ }^{9}$ we conducted the same series of Staudinger reactions involving imines $\mathbf{1 5}$ with substituents having different electronic effects, under microwave irradiation, both in a polar solvent (acetonitrile, a favorable microwave absorbance solvent) and in a non-polar solvent (toluene, an unfavorable microwave absorbance solvent) at $80{ }^{\circ} \mathrm{C}$ (Scheme 17). The results indicate that no obvious effect of microwave irradiation on the diastereoselectivity was observed in the Staudinger reactions. ${ }^{29}$

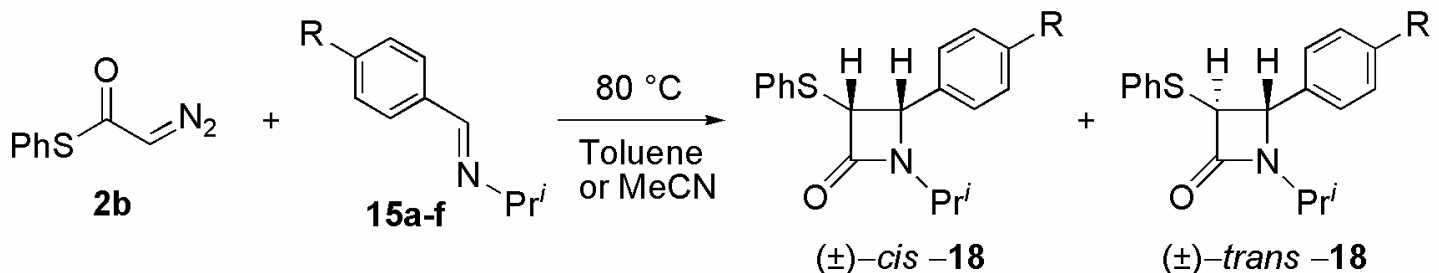

$\mathbf{a}: \mathrm{R}=\mathrm{H}, \mathbf{b}:=\mathrm{O}_{2} \mathrm{~N}, \mathbf{c}: \mathrm{R}=\mathrm{MeO}, \mathbf{d}: \mathrm{R}=\mathrm{Me}, \mathbf{e}: \mathrm{R}=\mathrm{Cl}, \mathbf{f}: \mathrm{R}=\mathrm{CF}_{3}$

Scheme 17. Influence of microwave irradiation on the diastereoselectivity in the Staudinger reaction.

We also investigated the effect of microwave irradiation on the diastereoselectivity via a series of Staudinger reactions involving different representative ketenes and the corresponding matched imines over a broad temperature range (Scheme 18). No obvious effect of microwave irradiation on the diastereoselectivity was observed in most cases. Although some slight effects were observed in some cases, we consider that these differences were caused by the temperature differences under microwave irradiation, because the reactants and their intermediates are more polar than the solvent and should locate in microscopic hot-spots in the reaction systems. The microwave- assisted reactions actually occur at a slightly higher temperature than the indicated one. $^{27 \mathrm{a}, 29}$ 


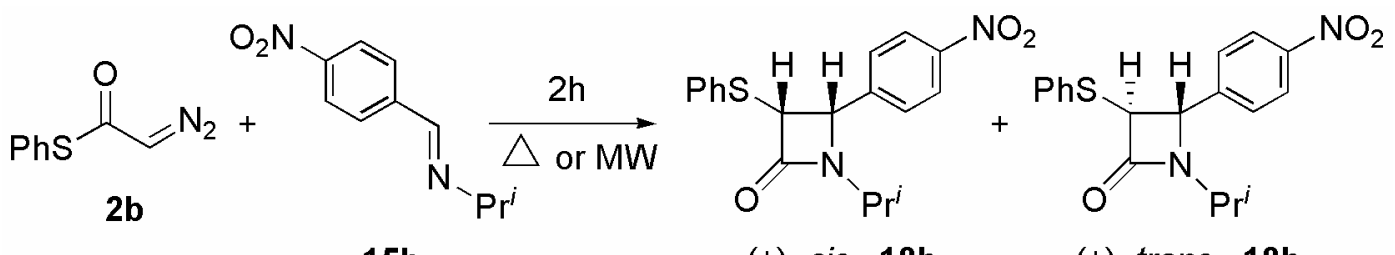

$15 b$

$( \pm)-$ cis $-\mathbf{1 8 b}$

$( \pm)-$ trans $-\mathbf{1 8 b}$

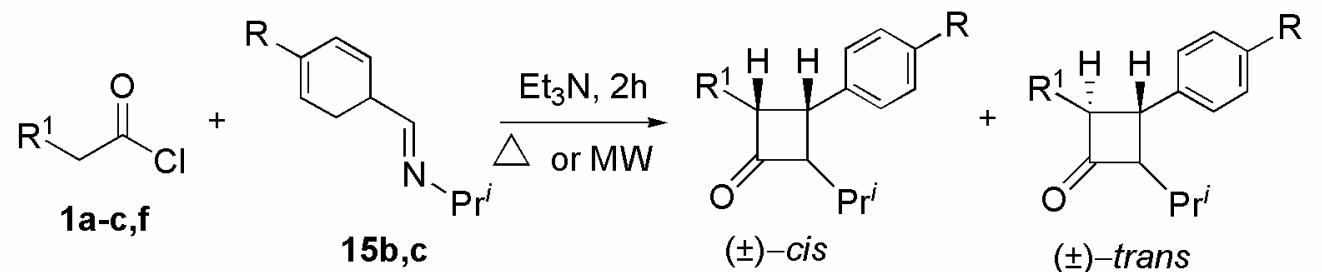

$25,26,27,24 b$

1a, 25: $R^{1}=P h O$, 1b, 26: $R^{1}=C l, 1 c, 27: R^{1}=P h t h N, ~ 1 f, ~ 24 b: R^{1}=M e$

15b, 24b, 26: $R=\mathrm{NO}_{2}, 15 c, 25,27: \mathrm{R}=\mathrm{MeO}$

Scheme 18. Influence of microwave irradiation on the diastereoselectivity in the Staudinger reaction at different temperatures.

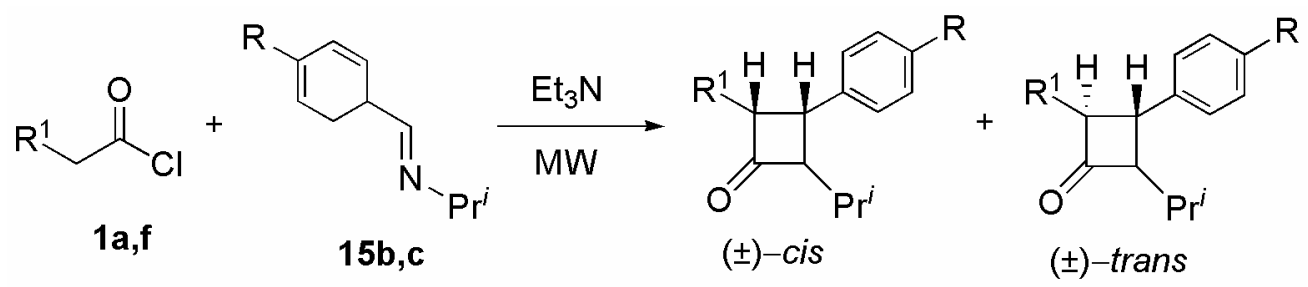

25, 24b

1a, 25: $R^{1}=P h O, 1 f, 24 b: R^{1}=M e, 15 b, 24 b: R=N O_{2}, 15 c, 25: R=M e O$

Scheme 19. Influence of microwave output on the diastereoselectivity in the Staudinger reaction.

Manhas and coworkers observed previously that microwave power outputs affected the diastereoselectivity in the Staudinger reaction. ${ }^{25}$ To further investigate the effect, we selected two representative ketene-imine systems to conduct Staudinger reactions with different microwave power outputs. Each reaction was conducted in two different aromatic solvents with similar polarity and different boiling points (Scheme 19). ${ }^{29}$ The solvent benzene, with low boiling point, was used to control the reaction temperature under different power outputs. The temperaturecontrolled reactions show similar diastereoselectivities under different outputs. ${ }^{29}$ For the reactions in high-boiling-point solvents, the reaction temperature increases with increasing power output, and the reactions show similar effects of temperature on the diastereoselectivity to those observed under thermal conditions. ${ }^{22}$

All of our results reveal that microwave irradiation indeed does not affect the diastereoselectivity in the Staudinger reaction. ${ }^{24,29}$ 


\section{Conclusions}

To summarize, the origin of the diastereoselectivity and influence of reaction conditions on the diastereoselectivity in the Staudinger reaction have been carefully investigated recently. The results indicate that (1) the diastereoselectivity is controlled by the competition between the direct ring-closure and the isomerization of the imine moiety in the zwitterionic intermediates generated from imines and ketenes; (2) electron-donating ketene substituents and electronwithdrawing imine substituents accelerate the direct ring-closure, leading to a preference for cis$\beta$-lactam formation; while electron-withdrawing ketene substituents and electron-donating imine substituents slow the direct ring-closure, leading to a preference for trans- $\beta$-lactam formation; (3) the electronic effect of the substituents on the isomerization is a minor factor in influencing the diastereoselectivity; (4) different ketene- generation pathways, solvent, additives usually existing in the reaction system, photo- and microwave- irradiations, do not affect the diastereoselectivity; (5) reaction temperature really affects the diastereoselectivity for some reactions and can be used to tune the diastereoselectivity. We hope that our results could provide some useful information to understand and control the diastereochemistry in the synthesis of 2azetidinones via the Staudinger reaction.

\section{Acknowledgements}

Thanks are due for contributions from Prof. Da-Ming Du, Libo Hu, Xu Huang, Lei Jiao, Bonan Li, Yong Liang, Dr. Chao Wang, Yikai Wang, Qianfeng Zhang, Prof. Qihan Zhang, Prof. Shiwei Zhang, Gang Zuo (in alphabetic order) for this project, and financial support from NSFC (No. 20772005).

\section{References and Notes}

1. (a) Chemistry and Biology of $\beta$-Lactam Antibiotics, Vols. 1-3; Morin, R. B.; Gorman, M., Eds.; Academic Press, 1982. (b) Southgate, R.; Branch, C.; Coulton, S.; Hunt, E. In Recent progress in the Chemical Synthesis of Antibiotics and Related Microbial Products, Luckacs, G., Ed.; Springer-Verlag, Berlin, 1993; Vol. 2, p 621. (c) Southgate, R. Contemp. Org. Synth. 1994, 1, 417.

2. For recent reviews on syntheses of $\beta$-lactams, see: (a) Van der Steen, F. H.; van Koten, G. Tetrahedron 1991, 47, 7503. (b) Palomo, C.; Aizpurua, J. M.; Ganboa, I.; Oiarbide, M. Eur. J. Org. Chem. 1999, 3223. (c) Singh, G. S. Tetrahedron 2003, 59, 7631.

3. Finke, P. E.; Shah, S. K.; Fletch, D. S. J. Med. Chem. 1995, 38, 2449.

4. (a) Banik, B. K.; Becker, F. F.; Banik, I. Bioorg. Med. Chem. 2004, 12, 2523. (b) Banik, B. K.; Banik, I.; Becker, F. F. Bioorg. Med. Chem. 2005, 13, 3611. (c) Rothstein, J. D.; Patel, 
S.; Regan, M. R.; Haenggeli, C.; Huang, Y. H.; Bergles, D. E.; Jin, L.; Hoberg, M. D.; Vidensky, S.; Chung, D. S.; Toan, S. V.; Bruijn, L. I.; Su, Z. Z.; Gupta, P.; Fisher, P. B. Nature 2005, 433, 73. (d) Miller, T. M.; Cleveland, D. W. Science 2005, 307, 361.

5. For a review, see: The Organic Chemistry of $\beta$-Lactams; Georg, G. I., Ed.; Verlag Chemie: New York, 1993.

6. (a) Moore, H. W.; Hernandez L. Jr.; Chambers, R. J. Am. Chem. Soc. 1978, 100, 2245. (b) Pacansky, J.; Chang, J. S.; Brown, D. W.; Schwarz, W. J. Org. Chem. 1982, 47, 2233. (c) Moore, H. W.; Hughes, G.; Srinivasachar, K.; Fernandez, M.; Nguyen, N. V.; Schoon, D.; Tranne, A. J. Org. Chem. 1985, 50, 4231. (d) Brady, W. T.; Gu, Y. Q. J. Org. Chem. 1989, 54, 2838. (e) Lynch, J. E.; Riseman, S. M.; Laswell, W. L.; Tschaen, D. M.; Volante, R.; Smith, G. B.; Shinkai, I. J. Org. Chem. 1989, 54, 3792. (f) Hegedus, L. S.; Montgomery, J.; Narukawa, Y.; Snustad, D. C. J. Am. Chem. Soc. 1991, 113, 5784. (g) Georg, G. I.; He, P.; Kant, J.; Wu, Z. J. J. Org. Chem. 1993, 58, 5771.

7. (a) Sordo, J. A.; González, J.; Sordo, T. L. J. Am. Chem. Soc. 1992, 114, 6249. (b) Cossio, F. P.; Ugalde, J. M.; Lopez, X.; Lecea, B.; Palomo, C. J. Am. Chem. Soc., 1993, 115, 995. (c) Arrieta, A.; Ugalde, J. M.; Cossio, F. P. Tetrahedron Lett. 1994, 35, 4465. (d) Cossio, F. P.; Arrieta, A.; Lecea, B.; Ugalde, J. M. J. Am. Chem. Soc., 1994, 116, 2085. (e) Arrieta, A.; Lecea, B.; Cossio, F. P. J. Org. Chem. 1998, 63, 5869. (f) Arrieta, A.; Cossio, F. P.; Fernandez, I.; Gomez-Gallego, M.; Lecea, B.; Mancheno, M. J.; Sierra, M. A. J. Am. Chem. Soc. 2000, 122, 11509. (g) Venturini, A.; González, J. J. Org. Chem. 2002, 67, 9089.

8. (a) Huang, X.; Xu, J. X. Heteroat. Chem. 2003, 14, 564. (b) Jiao, L.; Liang, Y.; Wu, C. Z.; Huang, X.; Xu, J. X. Chem. Res. Chin. Univ. 2005, 21, 59. (c) Xu, J. X.; Zuo, G.; Zhang, Q. H.; Chan, W. L. Heteroat. Chem. 2002, 13, 276. (d) Xu, J. X.; Zuo, G.; Chan, W. L. Heteroat. Chem. 2001, 12, 636. (e) Xu, J. X.; Wang, C.; Zhang, Q. H. Chin. J. Chem. 2004, 22, 1012. (f) Li, B. N.; Liang, Y.; Jiao, L.; Hu, L. B.; Du, D.-M.; Xu, J. X. Acta Chim. Sinica 2007, 65, 1649. (g) Xu, J. X.; Zuo, G.; Liang, B. Chem. Res. Chin. Univ. 2005, 21, 274.

9. Jiao, L.; Liang, Y.; Xu, J. X. J. Am. Chem. Soc. 2006, 128, 6060.

10. (a) Gong, L.; McAllister, M. A.; Tidwell, T. T. J. Am. Chem. Soc. 1991, 113, 6021. (b) López, R.; Sordo, T. L.; Sordo, J. A.; González, J. J. Org. Chem. 1993, 58, 7036. (c) Dumas, S.; Hegedus, L. S. J. Org. Chem. 1994, 59, 4967. (d) Hegedus, L. S.; Moser, W. H. J. Org. Chem. 1994, 59, 7779. (e) Alonso, E.; López-Ortiz, F.; del Pozo, C.; Peralta, E.; Macías, A.; González, J. J. Org. Chem. 2001, 66, 6333. (f) Macías, A.; Alonso, E.; del Pozo, C.; Venturini, A.; González, J. J. Org. Chem. 2004, 69, 7004.

11. It was reported that imines such as $C$-9-anthryl imines and $C$-2,6-disubstituted-phenyl imines partially exist in the $Z$ - configuration; however, they are seldom used in the Staudinger reaction. See: Bjorgo, J.; Boyd, D. R.; Watson, C. G.; Jennings, W. B.; Jerina, D. M. J. Chem. Soc, Perkin Trans. 2 1974, 1081.

12. (a) Podlech, J.; Linder, M. R. J. Org. Chem. 1997, 62, 5873. (b) Linder, M. R.; Podlech, J. Org. Lett. 1999, 1, 869. (c) Linder, M. R.; Frey, W. U.; Podlech, J. J. Chem. Soc. Perkin 
Trans. 1 2001, 2566. (d) Linder, M. R.; Podlech, J. Org. Lett. 2001, 3, 1849. (e) Kirmse, W. Eur. J. Org. Chem. 2002, 2193.

13. Jiao, L.; Liang, Y.; Zhang, Q. F.; Zhang, S. W.; Xu, J. X. Synthesis 2006, 659.

14. Seeman, J. I. Chem. Rev. 1983, 83, 83.

15. Wettermark, G. in The Chemistry of the Carbon-Nitrogen Double Bond; Patai, S., Ed.; Interscience: London, 1970; p565-596.

16. Eyring, H. J. Chem. Phys. 1935, 3, 107.

17. Jiao, L.; Zhang, Q. F.; Liang, Y.; Zhang, S. W.; Xu, J. X. J. Org. Chem. 2006, 71, 815.

18. (a) Banik, B. K.; Becker, F. F. Tetrahedron Lett. 2000, 41, 6551. (b) Banik, I.; Hackfield, L.; Banik, B. K. Heterocycles 2003, 59, 505.

19. Banik, B. K.; Lecea, B.; Arrieta, A.; de Cozar, A.; Cossio, F. P. Angew. Chem. Int. Ed. 2007, 46, 3028.

20. Wang, Y. K.; Liang, Y.; Jiao, L.; Du, D. M.; Xu, J. X. J. Org. Chem. 2006, 71, 6983.

21. Lopez, R.; Suarez, D.; Ruiz-Lopez, M. F.; Gonzalez, J.; Sordo, J. A.; Sordo, T. L. J. Chem. Soc. Chem. Comm. 1995, 1677.

22. Li, B. N.; Wang, Y. K.; Du, D. M.; Xu, J. X. J. Org. Chem. 2007, 72, 990.

23. Alcaide, B.; Almendros, P.; Salgado, N. R.; Rodriguez-Vicente, A. J. Org. Chem. 2000, 65, 4453.

24. Liang, Y.; Jiao, L.; Zhang, S. W.; Xu, J. X. J. Org. Chem. 2005, 70, 334.

25. Bose, A. K.; Banik, B. K.; Manhas, M. S. Tetrahedron Lett. 1995, 36, 213.

26. (a) Kappe, C. O. Angew. Chem. Int. Ed. 2004, 43, 6250. (b) de la Hoz, A.; Diaz-Ortiz, A.; Moreno, A. Chem. Soc. Rev. 2005, 34, 164.

27. (a) Xu, J. X. Prog. Chem. 2007, 19, 700. (b) Hosseini, M.; Stiasni, N.; Barbieri, V.; Kappe, C. O. J. Org. Chem. 2007, 72, 1417.

28. (a) Pollington, S. T.; Bond, G.; Moyes, R. B.; Whan, D. A.; Candlin, J. P.; Jennings, J. R. J. Org. Chem. 1991, 56, 1313. (b) Raner, K. D.; Strauss, C. R. J. Org. Chem. 1992, 57, 6231.

(c) Laurent, R.; Laporterie, A.; Dubac, J.; Berlan, J.; Lefeuvre, S.; Audhuy, M. J. Org. Chem. 1992, 57, 7099. (d) Stuerga, D.; Gonon, K.; Lallemant, M. Tetrahedron 1993, 49, 6229. (e) Kabza, K. G.; Chapados, B. R.; Gestwicki, J. E.; McGrath, J. L. J. Org. Chem. 2000, 65, 1210. (f) Kuhnert, N. Angew. Chem. Int. Ed. 2002, 41, 1863. (g) Strauss, C. R. Angew. Chem. Int. Ed. 2002, 41, 3589. (h) Garbacia, S.; Desai, B.; Lavastre, O.; Kappe, C. O. J. Org. Chem. 2003, 68, 9136.

29. Hu, L. B.; Wang, Y. K.; Li, B. N.; Du, D. M.; Xu, J. X. Tetrahedron 2007, 63, 9387. 


\section{Author's biographical data}

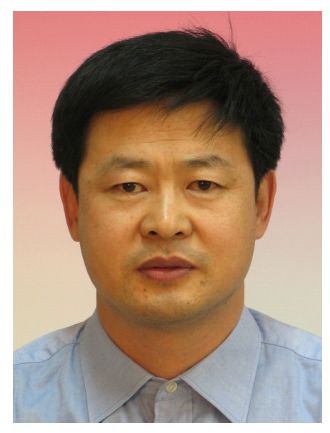

Jiaxi $\mathrm{Xu}$ completed his undergraduate training in chemistry at Peking University, Beijing, China, followed by doctoral studies at the same university. His thesis focused primarily on the cycloaddition reactions of 2,3-dihydro-1,5-benzoheteroazepines and water-soluble peptides in pollen. Postdoctoral studies in synthetic peptide vaccine against schistosomiasis were pursued at School of Pharmaceutical Sciences, Beijing Medical University. Back at Peking University, he was appointed as associate professor in 1994 and started his own work on the mass spectrometric study of tricyclic benzoheteroazepine derivatives, synthesis of aminoalkylphosphonic acid derivatives and phosphonopeptides, and substituted taurines, asymmetric catalysis, and stereochemistry in the synthesis of beta-lactams via the Staudinger reaction. He also worked as a visiting scholar at Department of Chemistry, The Chinese University of Hong Kong, during 1995; and as postdoctoral fellow at Department of Chemistry, Colorado State University, and Department of Microbiology and Immunology, School of Medicine, Vanderbilt University, USA, during 2000-2002. He was nominated professor at Peking University in 2004. He moved to the Faculty of Science, Beijing University of Chemical Technology in November 2007. His scientific interests focus on the organic synthesis, asymmetric catalysis, and peptide chemistry. He has co-authored about two hundreds publications in these fields. 